\title{
A multi criteria decision-making model for selecting hub port for Iranian marine industry
}

\author{
Amir Zabihi, Mohsen Gharakhani* and Arash Afshinfar
}

Department of Engineering, Qom University, Qom, Iran

\begin{tabular}{l}
\hline C H R O N I C L E \\
\hline Article history: \\
Received October 20, 2015 \\
Received in revised format \\
January 4, 2016 \\
Accepted February 102016 \\
Available online \\
February 112016 \\
\hline Keywords: \\
Analytic Hierarchy Process \\
(AHP) \\
Multi-criteria Decision Making \\
(MCDM) \\
Port location
\end{tabular}

\section{Introduction}

The hub location problem (HLP) is one of the most attractive research areas in location theory that has been focus of large number of articles during the past few decades. HLP tries to satisfy the demand of nodes and optimize the objective function such as total costs, using a Hub and spoke network, by considering several nodes as HUB and the remaining non-hubs as spokes. According to IMO publications (IMO, 2014), more than 90\% of world trade is carried out via the marine transportation. One of the main parts of goods transported via sea, is container carriage, which has been steadily growing except a small decrease around 2009, which was due to the economic crisis. It has been estimated that the container trade volume in 2017 to be more than 180 million twenty-foot equivalent units (TEUs), which has been depicted in Fig.1 (UNCTAD, 2015). Container shipping comprises shipping lines that transport containers based on long-term contracts from the spot markets (Du et al., 2011; Qi et.al, 2012). Large industrial customers have tens or even hundreds of containers to be transported weekly via container shipping. They usually sign a long-term contract; e.g., one-year or two-year, with transportation companies, which enable them, enjoy a very competitive freight rate.

\footnotetext{
* Corresponding author

E-mail address: m.gharakhani@gom.ac.ir (M. Gharakhani)

(C) 2016 Growing Science Ltd. All rights reserved.

doi: $10.5267 /$ j.uscm.2016.2.001
} 


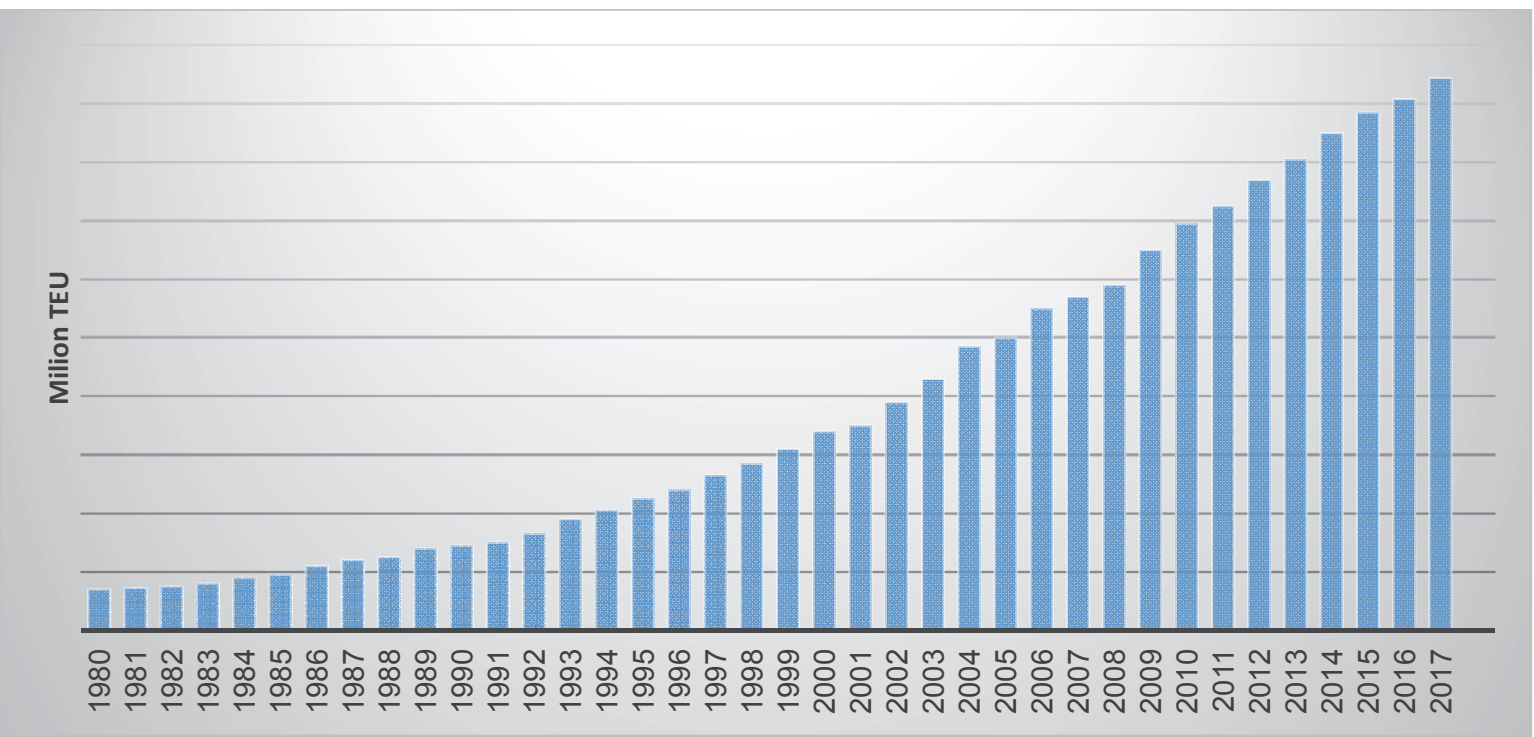

Fig. 1. Past and forecast global container volumes (1980-2015)

Fig. 1 shows a network for a service system with 15 nodes and three HUBs including A, K, F nodes. As can be seen, by selecting some of the nodes and hubs one can reduce the number of edges in the graph. Therefore, with using a hub network, we can satisfy demand more effectively by using fewer resources, than the fully connected graph.

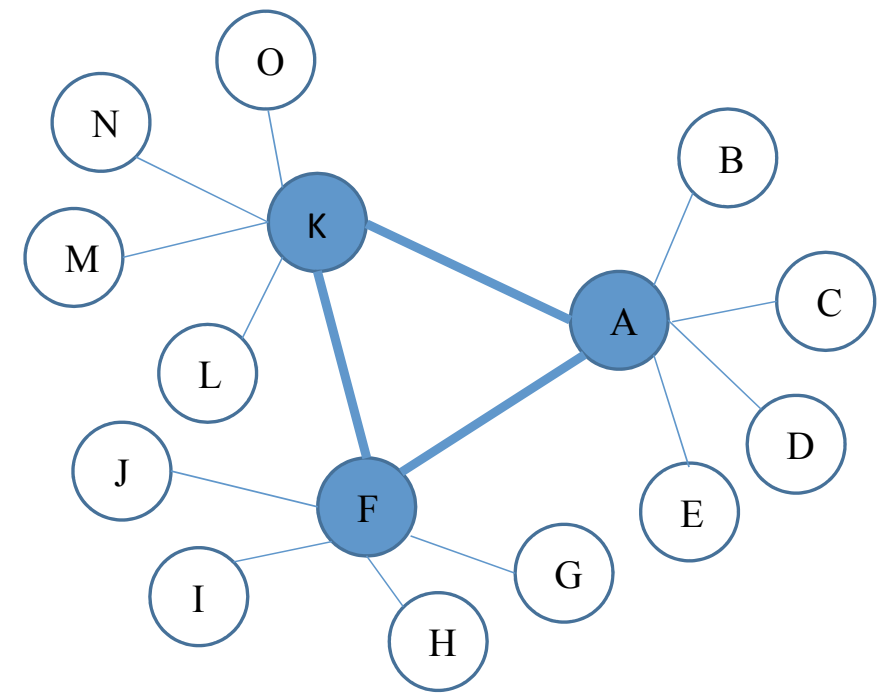

Fig. 2. A Hub and spoke network with 15 nodes and three HUBs

In the past, some researchers used strength, weakness, opportunity and threats (SWOT) analysis or mathematical programming method to analyze the transshipment competition relationship among different ports. However, few of them applied the multiple criteria decision-making (MCDM) method for selecting hub nodes.

In this study, we propose an MCDM model for evaluating and selecting the most appropriate ports as a HUB. The next section reviews the literature in Marine Hub and Spoke transportation area. In section 3, we provide a brief description of Analytic Hierarchy Process (AHP) method and finally to verify the application of MCDM, we presented a case study of locating a hub in southern Iran waters, among six major ports, including Bandar 
Abbas Port (IRBND), Imam Port (IRBIK), Assaluyeh Port (IRASA), Bushehr Port (IRBUZ), Chabahar Port (IRZBR) and Khorramshahr Port (IRKHO).

\section{Literature review}

Since the early days of marine containerization, there have been changes from direct call or multiport itineraries to hub and spoke service. Hub and spoke networks are widely used in the international shipping lines. One reason for increased interest in hub and spoke transshipment networks is associated with the trend towards deployment of bigger ships. Post-Panamax ships of 5000-7500 TEU and above now dominate the major international trades. Many influential factors have been studied for the selection of transshipment container ports in the literature. Hayuth and Fleming (1994) proposed the most common characteristics of a transshipment port including (a) location, (b) operation, (c) infrastructure and (d) Electronics Data Interchange (EDI). However, not every port that meets these criteria will receive transshipment port status. Hence, the issue of transshipment port selection is complex and cannot always be fully explained in terms of rational elements.

Slack (1985) used the following 11 criteria for port selection: (a) port security, (b) size of port, (c) inland freight rates, (d) port charges, (e) quality of customs handling, (f) free time, (g) congestion, (h) port equipment (i) number of sailings, (j) proximity of port, and (k) possibility of inter-modal links.

James and Gail (1998) justified the widespread belief that frequency of shipping service is a main reason for choice of seaport in cargo movement. Time on the route and labor problems at ports is major concerns of freight forwarders. The abovementioned factors also could be included in the criteria for the selection of transshipment ports. Thomson (1998) found that the key successful factors of the transshipment port including: (a) the length of berthing time at port, (b) the loading/discharge rate, (c) the available number of berths, (d) the quantity of containerized cargo, (e) the port facility, (f) the links of port to major consumers market, $(\mathrm{g})$ the working hours of ports.

Sternberg (2000) stated that the Gioia Tauro port's key successful factors to make her as the Mediterranean container transshipment port are as follows: (a) superior geographical location, (b) the knowledge of market of marine container operators, (c) the flexible operation process, (d) continuous investment in the infrastructure and facility, (e) the operation of related business.

Ernst (2001) found that to achieve large-scale transshipment requires: (a) increase in service frequency, (b) buildup of shipping and inter-modal alliance, and (c) sharing of space on each other's ships, inland depots, feeders, container terminals, and container inventories.

Kuo and Chu (2000) constructed a decision-making model for the selection of calling container port using the mathematical programming method. Chou et al. (2003) discussed some important factors that influent the selection of container port and develop a transportation demand split model for international ports by the mathematical programming. Chou et al. (2003a, 2003b) discussed some important factors that influent on the selection of container port and compare the Stackelberg port choice model and Equilibrium port choice model. They find out factors that influent Asia-America oceangoing carriers' selection of container port are different from factors that influent Intra-Asia coasting carriers' selection of container port.

Malchow and Kanafani (2004) used an alternative form of the discrete choice model to analyze the distribution of maritime shipments among US ports. They modeled the distribution as a function of the characteristics that describe each shipment and each port. Finally, they found that the most significant characteristics of a port is its location.

Baird (2006) applied a specific research methodology designed to evaluate and compare competing seaport locations within a given region as the optimal site for international container transshipment activity. The focus was on container transshipment hub locations in northern Europe. Transport distance and associated shipping costs were calculated for existing hub locations and these were then compared with a new proposed transshipment location in the region, in the instance the vast natural 
deep-water harbor at Scapa Flow in the Orkney Islands. Dahlberg and May (1985) utilized the simplex method to determine the optimal location of energy facilities. Tompkins et al (1984) introduced a method that used the preference theory to assign weights to subjective factors by making all possible pairwise comparisons between factors. Spohrer and Kmak (1984) proposed a weight factor analysis method to integrate the quantitative data and qualitative rating to choose a plant location from numerous alternatives. Stevenson (1993) proposed a cost-volume analysis method to select the best plant location. MCDM methods are very strong to deal with the problem of ranking and selecting locations under multiple criteria (Hwang, \& Yoon, 1981; Rietveld \& Ouwersloot, 1992). Theree are many recent research papers using different method within MCDM area (Gharakhani et al., 2011; Athawale \& Chakraborty, 2011; Soltanmohammad et al., 2013).

In this article, we assume that criteria are independent and there are not any interactions among them. Then we summarize the criteria that are in a literature review to create a hierarchical structure (Fig. 3). We utilizing a hybrid methodology through combining AHP and TOPSIS, to evaluate and ranking of the ports located in southern Iran.

\section{Methodology}

\subsection{Analytical hierarchy process}

AHP is one of the most famous multi-criteria decision-making techniques developed by Saaty (1980). This method was developed in the 1670s and can be used when the decision-making is faced to several Rival options and decision criteria. Criteria that can be raised in AHP are qualitative and quantitative criteria (Saaty, 1988). In AHP, hierarchy decision Tree shows criteria for comparison and alternatives for evaluating. This method begins by providing a decision tree via decision makers and then paired comparisons are made. These comparisons determine weight of each criterion to evaluating the alternatives. In final, the logic of this method is combining the pairwise comparison matrices to obtained optimum decision. AHP contains five steps as follow:

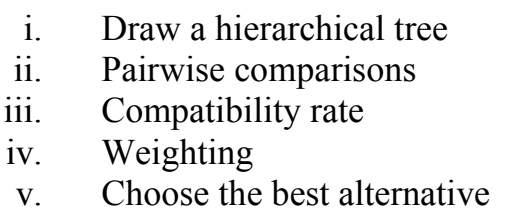

Step 1: Draw a hierarchical tree: In general, understanding a problem is difficult for human and may be different and some people may not consider important aspects of the problem. Therefore, decomposition of a generalized problem to several minor problems helps to effectiveness understand of problem. By doing this, relationships and concepts of decision problem and the relevance of each element with other elements, accurately understand. Hierarchical tree has several levels as follow:

i. First level: Goal

ii. Second level: The main criteria

iii. End level: Alternatives

Step 2: Pairwise comparisons: To do this, we must have a scale to measure data and conversion qualitative data to quantitative data. Error! Reference source not found. shows the Practical scale for pairwise comparison.

Table 1

Scales used for paired comparisons

\begin{tabular}{ll}
\hline Value & The importance of pairwise comparison \\
\hline 1 & Preferably the same \\
2 & Identical to relatively little \\
3 & Relatively little \\
4 & Moderately to strongly preferred \\
5 & Strongly preferred \\
6 & Strong to very strong preference \\
7 & Very strong preference \\
\hline 9 & Highly preference to Infinitely preference \\
\hline
\end{tabular}


After the formation of the pairwise comparison matrix of criteria, their relative weights are calculated. First, the sum of each column of paired comparisons matrix is calculated. The amount of each element is divided by sum of the itself column to matrix be normalized (Eq. (1)). Then average values of each rows of normalized matrix gives the weight vector parameters form (Eq. (2)).

$$
\begin{aligned}
r_{i j} & =\frac{a_{i j}}{\sum_{i=1}^{m} a_{i j}} \\
W_{i} & =\frac{\sum_{i=1}^{n} r_{i j}}{n}
\end{aligned}
$$

In Eq. (1) and Eq. (2), $m$ and $n$ are the number of alternatives (rows) and number of criteria (column), respectively. Also, $a_{i j}$ and $r_{i j}$ are elements of pairwise comparison matrix and elements of normalized pairwise comparison matrix, respectively. $W_{i}$ represents the weight of criterion $i$.

Step 3: calculate compatibility rate: compatibility rate is a mechanism that determines the compatibility of comparisons. This mechanism shows how much we trust to priorities obtained from members or combined table. Experience has shown that if the compatibility rate, is less than 0.1 , compatibility comparisons can be accepted, otherwise, comparisons must be executed one more time. If the number of respondents is more than one, compatibility rate of comparison matrices will be calculate based on geometric mean of answers.

Calculating the compatibility rate will take place in six stages. These stages are including: (1) Total weight vector (2) Consistency vector (3) The mean of Consistency vector $\left(\lambda_{\max }\right)$ (4) The consistency index (CT) (5) Random index (RI) and (6) Inconsistency ratio (CR). Each of these amounts is calculated by Eq. (3), Eq.(4) and Eq.(5). Table 2 shows random index values for comparison of different alternatives.

$$
\begin{aligned}
& \lambda_{\text {max }}=\frac{1}{N} \sum_{i=1}^{n} \frac{\bar{a} W_{i j}}{W_{i j}} \\
& C T=\frac{\lambda_{\max }-n}{n-1} \\
& C R=\frac{C I}{R I}
\end{aligned}
$$

Table 2

Random index value

\begin{tabular}{lllllllllll}
\hline $\mathrm{N}$ & 1 & 2 & 3 & 4 & 5 & 6 & 7 & 8 & 9 & 10 \\
\hline $\mathrm{RI}$ & 0 & 0 & 0.58 & 0.9 & 1.12 & 1.24 & 1.32 & 1.41 & 1.45 & 1.49 \\
\hline
\end{tabular}

Step 4: Weighting: At this step, we determine the final score of each alternative. Although, there are few different methods for calculating the weight of criteria, but the most popular ones include: (1) the least squares method (2) The least squares logarithmic method (3) special vector method (4) estimated approximate methods. Note that the approximate methods include total row, total column, arithmetic mean, geometric mean. Eq.(6) identifies priority by taking weight in all levels of decision trees.

$$
V_{H}=\sum_{k=1}^{n} W_{k}\left(g_{i j}\right)
$$

where, $V_{H}, W_{k}$ and $g_{i j}$ is final weight of alternative $H$, weight of criteria $k$ and score of alternative $i$ from the perspective of criteria $j$, respectively.

Step 5: Choose the best alternative: Finally, based on the final weight obtained from the previous step we rank alternatives in non-increasing order. Obviously, we can select the first alternative as the best one.

\subsection{TOPSIS}

Chen and Hwang (1992) proposed the TOPSIS method with reference to Hwang and Yoon (1981). The basic principle is that the chosen alternative should have the shortest distance from the positive-ideal solution that 
maximizes the benefit and also minimizes the total cost, and the farthest distance from the negative-ideal solution that minimizes the benefit and also maximizes the total cost (Opricovic \& Tzeng, 2004).

The TOPSIS method consists of the following steps:

Step 1: Calculate the normalized decision matrix. The normalized value $r_{i j}$ is calculated as:

$$
r_{i j}=\frac{X_{i j}}{\sqrt{\sum_{i=1}^{m} X_{i j}^{2}}} \quad \forall i . j
$$

Step 2: Calculate the weighted normalized decision matrix. The weighted normalized value $v_{i j}$ is calculated as:

$$
v_{i j}=w_{j} r_{i j} \quad \forall i . j
$$

where $w_{j}$ is the weight of the jth criterion, and $\sum_{j=1}^{m} w_{j}=1$.

Step 3: Determine the positive-ideal and negative-ideal solution.

$$
\begin{aligned}
& A^{+}=\left\{v_{1}^{+} \ldots . . v_{m}^{+}\right\}=\left\{\left(\max _{i} v_{i j} \mid j \in C_{b}\right) .\left(\min _{i} v_{i j} \mid j \in C_{c}\right)\right\} \\
& A^{-}=\left\{v_{1}^{-} \ldots . . v_{m}^{-}\right\}=\left\{\left(\min _{i} v_{i j} \mid j \in C_{b}\right) .\left(\max _{i} v_{i j} \mid j \in C_{c}\right)\right\}
\end{aligned}
$$

where $C_{b}$ is associated with benefit criteria and $C_{c}$ is associated with cost criteria.

Step 4: Calculate the distance measures, using the $m$ dimensional Euclidean distance. The distance of each alternative from the positive-ideal solution is given as:

$$
d_{i}^{+}=\sqrt{\sum_{j=1}^{n}\left(V_{i j}-V_{j}^{+}\right)^{2}} \quad \forall i
$$

Similarity, the distance from the negative-ideal solution is given as:

$$
d_{i}^{-}=\sqrt{\sum_{j=1}^{n}\left(V_{i j}-V_{j}^{-}\right)^{2}} \quad \forall i
$$

Step 5: Calculate the relative closeness to the positive-ideal solution. The relative closeness of the alternative $A_{i}$ with respect to $A^{*}$ is defined as:

$$
C_{i}^{*}=\frac{d_{i}^{-}}{d_{i}^{-}+d_{i}^{+}} \quad \forall i
$$

Step 6: Rank the preference order.

The index values of $C_{i}^{*}$ lie between 0 and 1 . The larger index value means the closer to positive-ideal solution for alternatives.

\section{Case study}

In this section, we investigate the MCDM model using a real world case study. In order to have a clear understanding over the candidate hub ports, we provide a brief statistics of main Iranian ports in Table 3 . The criteria that used to select the most suitable port as a hub port and the hierarchical structure is shown in Fig. 3. To obtain pairwise comparisons between the criteria and the alternatives, a questionnaire designed and filled by five experts of Iran's maritime transportation table 4 and table 5, show the pairwise comparisons of the first decision maker for the main criteria and port efficiency, respectively. We use specialized software of AHP method called Expert Choice version 11 to perform calculations. 
Table 3

Main factors and technical statistics of Iranian ports

\begin{tabular}{|c|c|c|c|c|c|c|}
\hline & Imam Port & Bandar Abbas Port & Bushehr Port & Chabahar Port & Assaluyeh Port & Khorramshahr Port \\
\hline UNLOCODE (ECE, U, 1998) & IRBIK & IRBND & IRBUZ & IRZBR & IRASA & IRKHO \\
\hline Longitude, Latitude & 49-04E, 30-25 N & $56-04 \mathrm{E}, 27-16 \mathrm{~N}$ & $50-50 \mathrm{E}, 28-59 \mathrm{~N}$ & $\begin{array}{l}60-37 \mathrm{E}, 25- \\
17 \mathrm{~N}\end{array}$ & $52 \mathrm{E}, 27 \mathrm{~N}$ & $48 \mathrm{E}, 30 \mathrm{~N}$ \\
\hline Distance from Tehran (KM) & 927 & 1563 & 1196 & 2322 & 1280 & 940 \\
\hline $\begin{array}{l}\text { Distance from center of the } \\
\text { province }(\mathrm{KM})\end{array}$ & 185 & 25 & - & 717 & 279 & 139 \\
\hline $\begin{array}{l}\text { Distance from the nearest airport } \\
(\mathrm{KM})\end{array}$ & 25 & 50 & 3 & 40 & 14 & 15 \\
\hline $\begin{array}{l}\text { The temperature range during the } \\
\text { year }\left({ }^{\circ} \mathrm{C}\right)\end{array}$ & +5 to +6 & +10 to +46 & +5 to +40 & +22 to +34 & +5 to +50 & +5 to +6 \\
\hline Connection to other cities & $\begin{array}{l}\text { road, railway and } \\
\text { airlines }\end{array}$ & $\begin{array}{l}\text { road, railroad and } \\
\text { airlines }\end{array}$ & road and railroad & $\begin{array}{l}\text { road and } \\
\text { airline }\end{array}$ & $\begin{array}{l}\text { road, air and } \\
\text { railway }\end{array}$ & $\begin{array}{l}\text { road, airline and } \\
\text { railway }\end{array}$ \\
\hline The humidity range during the & $\% 15$ to $\% 99$ & $\% 20$ to $\% 95$ & $\% 21$ to $\% 98$ & $\% 62$ to $\% 89$ & $\% 15$ to $\% 99$ & $\% 15$ to $\% 99$ \\
\hline Yards (square meter) & $10,980,790$ & $1,598,000$ & 668,900 & 365000 & $112,423,442$ & $6,456,839$ \\
\hline Warehouses (square meter) & 287,940 & 164,000 & 30,312 & 6000 & $1,985,576$ & 2,475 \\
\hline Capacity (Ktons) & $45-60$ & $45-70$ & - & $2-25$ & $132-311$ & $15-20$ \\
\hline Barges & 9 & 5 & 9 & 9 & 19 & 3 \\
\hline Hopper for cereal & 5 & 5 & 0 & 4 & 6 & 1 \\
\hline Tractors & 53 & 95 & 18 & 12 & 33 & 22 \\
\hline Top lifts & 5 & 5 & 1 & 1 & 3 & 2 \\
\hline Lift-truck & 119 & 136 & 29 & 15 & 177 & 88 \\
\hline Trans-containers & 2 & 10 & 0 & 1 & 7 & 0 \\
\hline Gantry cranes & 2 & 4 & 0 & 0 & 2 & 2 \\
\hline Yard cranes & 40 & 51 & 28 & 6 & 46 & 24 \\
\hline Boats & 10 & 17 & 7 & 2 & 79 & 8 \\
\hline Tugboats & 11 & 10 & 1 & 3 & 3 & 8 \\
\hline Dredges & 5 & 1 & 1 & 0 & 8 & 0 \\
\hline Cranes & 6 & 6 & 0 & 0 & 14 & 5 \\
\hline Push trucks & 10 & 10 & 0 & 0 & 32 & 7 \\
\hline
\end{tabular}

Table 4

Pairwise comparison of criteria with respect to the port choice (the first expert)

\begin{tabular}{|c|c|c|c|c|c|c|}
\hline & Port location & Hinterland economy & Port equipment & Port efficiency & Cost & Other condition \\
\hline Port location & 1 & 3 & 4 & 4 & 0.5 & 1 \\
\hline Hinterland economy & 0.33 & 1 & 3 & 3 & 1 & 0.5 \\
\hline Port equipment & 0.25 & 0.33 & 1 & 1 & 2 & 0.5 \\
\hline Port efficiency & 0.25 & 0.33 & 1 & 1 & 1 & 0.5 \\
\hline Cost & 2 & 1 & 0.66 & 1 & 1 & 0.5 \\
\hline Other condition & 1 & 2 & 2 & 2 & 2 & 1 \\
\hline
\end{tabular}

Compatibility rate: 0.1

Table 5

Pairwise comparison with respect to port efficiency (the first expert)

\begin{tabular}{lllll}
\hline & Port berthing time length & Containers handling efficiency & Container yard efficiency & Custom efficiency \\
\hline Port berthing time length & 1 & 0.25 & 0.25 & 0.25 \\
Containers handling efficiency & 4 & 1 & 0.5 & 0.5 \\
Container yard efficiency & 4 & 2 & 1 & 0.5 \\
Custom efficiency & 4 & 2 & 2 & 1 \\
\hline
\end{tabular}

Compatibility rate: 0.03

Due to the geographical position of Iran and its relationship with the open sea through the southern ports, most commercial marine transportation of the country is through these ports. The aim of this study is to determine one of these candidate ports as main hub So that all International Iran's commercial shipping through this HUB port and all other remaining ports connected to the main HUB. Table 6 shows the pairwise comparison of the first expert for ports with respect to container volume export / import criteria.

Table 6

Pairwise comparison of ports with respect to volume of export/import containers (the first expert)

\begin{tabular}{lcccccc}
\hline & IRBIK & IRBND & IRBUZ & IRZBR & IRASA & IRKHO \\
\hline IRBIK & 1 & 0.25 & 3 & 3 & 2 & 2 \\
IRBND & 4 & 1 & 5 & 5 & 4 & 5 \\
IRBUZ & 0.33 & 0.2 & 1 & 2 & 0.5 & 1 \\
IRZBR & 0.33 & 0.2 & 0.5 & 1 & 1 & 1 \\
IRASA & 0.5 & 0.25 & 2 & 1 & 1 & 1 \\
IRKHO & 0.5 & 0.2 & 1 & 1 & & 1 \\
\hline Compatibility rate: 0.02 & & & & &
\end{tabular}




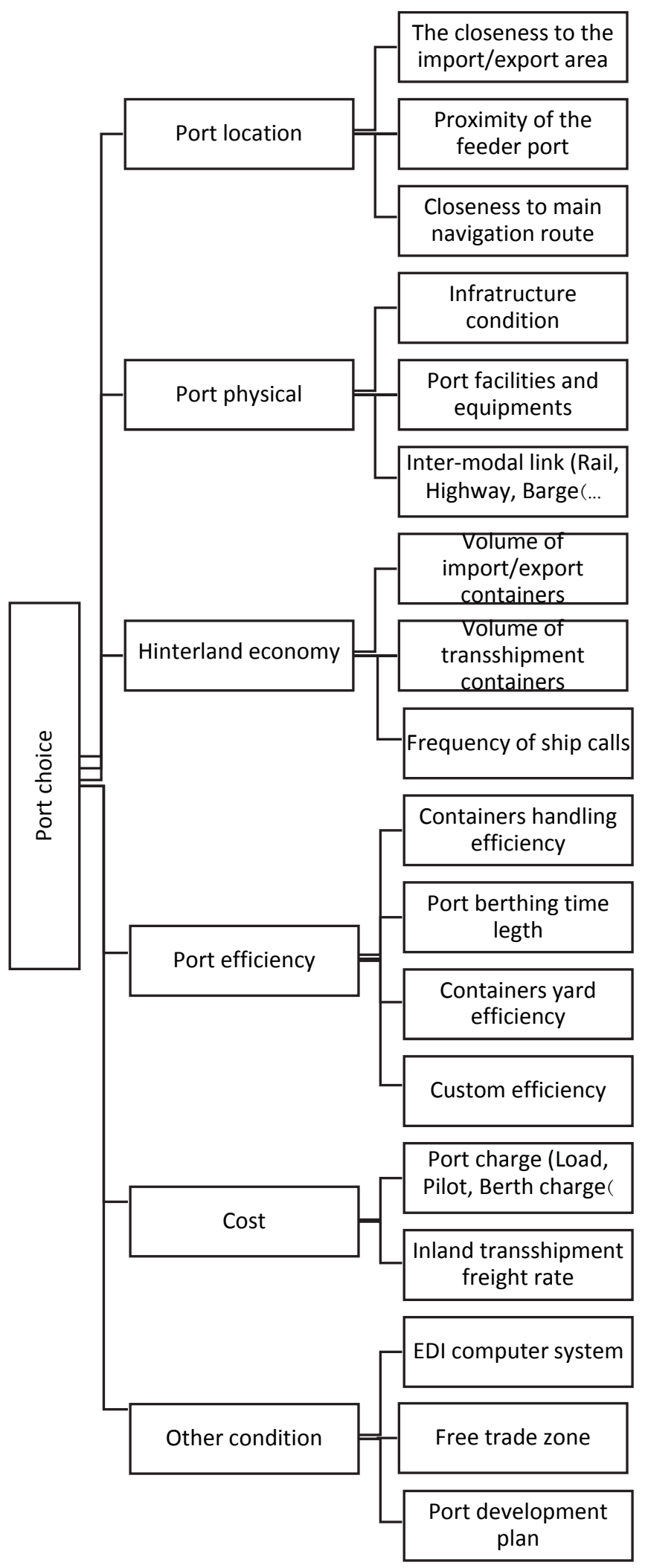

Fig. 3. Hierarchical structure the most appropriate port as a hub 
Table 7

Weight of criteria and sub-criteria

\begin{tabular}{|c|c|c|c|c|c|}
\hline Main criteria & Criteria weight & Sub-criteria & $\mathrm{CR}$ & Final weight & Rank \\
\hline \multirow[t]{3}{*}{ Port location } & 0.62 & The closeness to import/export area & 0.02 & 0.683 & 2 \\
\hline & & Proximity to feeder port & & 0.117 & 16 \\
\hline & & Closeness to navigation routes & & 0.2 & 12 \\
\hline \multirow[t]{3}{*}{ Port physical } & 0.088 & Infrastructure condition & 0.05 & 0.232 & 10 \\
\hline & & Port facilities and equipment & & 0.584 & 3 \\
\hline & & Inter-modal link & & 0.184 & 13 \\
\hline \multirow[t]{3}{*}{ Hinterland economy } & 0.16 & Volume of import/export containers & 0.01 & 0.416 & 8 \\
\hline & & Volume of transshipment containers & & 0.126 & 15 \\
\hline & & Frequency of ship call & & 0.458 & 6 \\
\hline \multirow[t]{4}{*}{ Port efficiency } & 0.088 & Containers handling efficiency & 0.05 & 0.21 & 11 \\
\hline & & Port berthing time length & & 0.074 & 18 \\
\hline & & Containers yard efficiency & & 0.297 & 9 \\
\hline & & Custom efficiency & & 0.419 & 7 \\
\hline \multirow[t]{2}{*}{ Cost } & 0.173 & Port charge & 0 & 0.5 & 4 \\
\hline & & Inland transshipment freight rate & & 0.5 & 5 \\
\hline \multirow[t]{3}{*}{ Other condition } & 0.272 & EDI computer system & 0.07 & 0.109 & 17 \\
\hline & & Free trade zone & & 0.748 & 1 \\
\hline & & Port development plan & & 0.143 & 14 \\
\hline
\end{tabular}

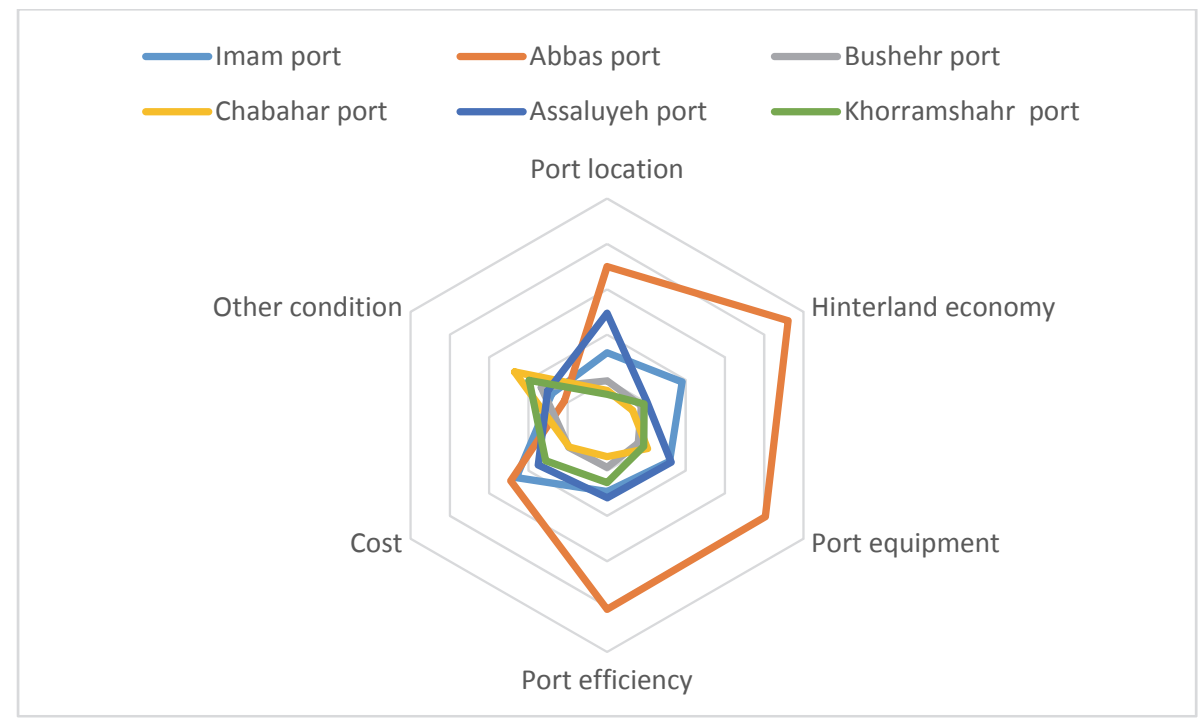

Fig. 4. The weight of each port in terms of the criteria

We take the geometric average from pairwise comparisons of five experts by the Eq.(7). We then used the Obtained comparison matrix as pairwise comparison matrix for using in the AHP method.

$$
a_{i j}=\left(\prod_{k}\left(a_{i j}^{k}\right)^{W_{k}}\right)^{\frac{1}{\sum_{k} W_{k}}}
$$

Table 7 shows respective weights of each criteria. According to this table, the most important criterion for selection port in this study is port location. Fig. 4 shows the score of each port according to the main criteria. We then used the weights of criterion obtained from AHP technique as the inputs for TOPSIS method. For instance, Table 8 shows the decision matrix which filled by first expert which; Because of the lack of space, we transposed it. 
Table 8

Decision matrix (Expert 1)

\begin{tabular}{|c|c|c|c|c|c|c|}
\hline & & & & Ports & & \\
\hline Criteria & IRBIK & IRBND & IRBUZ & IRZBR & IRASA & IRKHO \\
\hline The closeness to import/export area & 6 & 9 & 4 & 5 & 5 & 6 \\
\hline Proximity to feeder port & 5 & 9 & 5 & 6 & 5 & 5 \\
\hline Closeness to navigation routes & 6 & 8 & 4 & 5 & 5 & 3 \\
\hline Infrastructure condition & 5 & 8 & 5 & 5 & 6 & 5 \\
\hline Port facilities and equipment & 4 & 9 & 2 & 2 & 3 & 2 \\
\hline Inter-modal link & 6 & 8 & 5 & 4 & 5 & 4 \\
\hline Volume of import/export containers & 4 & 7 & 3 & 2 & 3 & 3 \\
\hline Volume of transshipment containers & 4 & 7 & 3 & 2 & 3 & 3 \\
\hline Frequency of ship call & 5 & 7 & 3 & 3 & 5 & 5 \\
\hline Containers handling efficiency & 6 & 7 & 6 & 5 & 7 & 5 \\
\hline Port berthing time length & 5 & 8 & 3 & 2 & 4 & 3 \\
\hline Containers yard efficiency & 6 & 8 & 5 & 4 & 5 & 5 \\
\hline Custom efficiency & 7 & 7 & 6 & 6 & 5 & 8 \\
\hline Port charge & 8 & 6 & 7 & 8 & 7 & 9 \\
\hline Inland transshipment freight rate & 8 & 8 & 6 & 6 & 6 & 8 \\
\hline EDI computer system & 8 & 8 & 6 & 4 & 7 & 8 \\
\hline Free trade zone & 7 & 7 & 7 & 8 & 5 & 9 \\
\hline Port development plan & 7 & 7 & 6 & 9 & 8 & 8 \\
\hline
\end{tabular}

Then, by multiplying the weights vector into normalized matrix, we obtained the weighted matrix. In TOPSIS method, there are two types of criteria including positive $(+)$ and negative (-) dimension. Bearing in mind our proposed criteria in Fig. 3, the nature of all of the presented factors are the greater the better i.e. positive. Therefore according to the definition, the positive-ideal and negative-ideal solution have been calculated in Table 9.

Table 9

Positive-Ideal and negative-ideal solution

\begin{tabular}{lllc}
\hline Type of Criteria & Criteria & $\boldsymbol{V}_{j}^{-}$ & $\boldsymbol{V}_{j}^{+}$ \\
\hline Positive & The closeness to import/export area & 0.047261 & 0.106336 \\
Positive & Proximity to feeder port & 0.010166 & 0.018299 \\
Positive & Closeness to navigation routes & 0.011611 & 0.007218 \\
Positive & Infrastructure condition & 0.009462 & 0.011549 \\
Positive & Port facilities and equipment & 0.004801 & 0.042579 \\
Positive & Inter-modal link & 0.013587 & 0.009602 \\
Positive & Volume of import/export containers & 0.004115 & 0.047553 \\
Positive & Volume of transshipment containers & 0.018449 & 0.014403 \\
Positive & Frequency of ship call & 0.008721 & 0.043047 \\
Negative & Containers handling efficiency & 0.001156 & 0.00623 \\
Positive & Port berthing time length & 0.007565 & 0.004623 \\
Positive & Containers yard efficiency & 0.011456 \\
Positive & Custom efficiency & 0.042035 \\
Negative & Port charge & 0.039953 \\
Negative & Inland transshipment freight rate & 0.005782 \\
Positive & EDI computer system & 0.047683 \\
Positive & Free trade zone & 0.010516 & 0.018329 \\
Positive & Port development plan & 0.028023 & 0.029964 \\
\hline
\end{tabular}

Firstly, by using Eq. (11), Eq. (12) distance of the positive-ideal and negative-ideal solutions calculated and then value of $C_{i}^{*}$ is calculated for each of the candidate ports. The final calculations is presented in Table 10 in details. The First and the second columns of Table 10 represent the distance from the positive-ideal and negative-ideal solutions and the fourth column shows the amount of $C_{i}^{*}$ and the fifth column shows the final ranking.

Table 60

The distance from the positive-ideal and negative-ideal solutions and final ranking

\begin{tabular}{lcccc}
\hline Ports & $\boldsymbol{d}_{\boldsymbol{i}}^{+}$ & $\boldsymbol{d}_{\boldsymbol{i}}^{-}$ & $\boldsymbol{d}_{\boldsymbol{i}}^{+}+\boldsymbol{d}_{\boldsymbol{i}}^{-}$ & $\boldsymbol{C}_{\boldsymbol{i}}^{*}$ \\
\hline IRBIK & 0.05620002 & 0.04004078 & 0.096241 & Final ranking \\
IRBND & 0.02207497 & 0.08729604 & 0.109371 & 3 \\
IRBUZ & 0.08258387 & 0.02523263 & 0.107817 & 0.798164 \\
IRZBR & 0.07556865 & 0.0343929 & 0.109962 & 0.234033 \\
IRASA & 0.07610588 & 0.025497 & 0.101603 & 0.312772 \\
IRKHO & 0.0642856 & 0.04814869 & 0.112434 & 0.250948 \\
\hline
\end{tabular}




\section{Conlusion}

In this study, we have developed a hybrid MCDM method for selecting container hub. The accuracy and applicability of the proposed method has been verified by a case study for an iranian port. The results have shown that the proposed method could be used to make decisions about the choice of the best container hub for shipping companies. By using the results of this research, managers of shipping lines will be able to identify the Iranian conatiner hub port and then make more precise decisions in determinining the most cost effective voyage loop for their liners.

Based on the results, we can rank the most designated Iranian container hub ports as: (1) IRBND (2) IRASA (3) IRBIK (4) IRKHO (5) IRZBR (6) IRBUZ. Meanwhile, among the main criteria, port location criteria have higher rank.

By using the results of this research the decision makers in each port can attract shipping companies to choose a port as a container hub with effective actions in mentioned factors such as lowering the cost of loading and discharge, increasing the use of EDI, and development of equipmenets and services in the ports.

\section{Refrences}

Athawale, V. M., \& Chakraborty, S. (2011). A comparative study on the ranking performance of some multi-criteria decision-making methods for industrial robot selection. International Journal of Industrial Engineering Computations, 2(4), 831-850.

Baird, A. J. (2006). Optimising the container transhipment hub location in northern Europe. Journal of Transport Geography, 14(3), 195-214.

Chen, S.-J., \& Hwang, C.-L. (1992). Fuzzy multiple attribute decision making methods: Springer.

Chew, E. P., Lee, L. H., \& Tang, L. C. (2011). Advances in Maritime Logistics and Supply Chain Systems: World Scientific.

Chien-Chang, C., Ching-Wu, C., \& Liang, G.-S. (2003). Competitiveness analysis of major ports in Eastern Asia. Journal of the Eastern Asia Society for Transportation Studies, 5, 1-16.

Chou, C.-C. (2007). A fuzzy MCDM method for solving marine transshipment container port selection problems. Applied Mathematics and Computation, 186(1), 435-444.

Chou, C.-C., Chu, C.-W., \& Liang, G.-S. (2003a). Comparison of two models for port choice.

Chou, C.-C., Chu, C.-W., \& Liang, G.-S. (2003b). A transportation demand split model for international ports in Taiwan area.

Dahlberg, M., \& May, J. (1985). Linear-programming for siting of energy facilities. Energy Engineering, 82(1), 5-14.

Du, Y., Chen, Q., Quan, X., Long, L., \& Fung, R. Y. (2011). Berth allocation considering fuel consumption and vessel emissions. Transportation Research Part E: Logistics and Transportation Review, 47(6), 1021-1037.

Ernst, G. (2001). Economics of transportation in container shipping logistics. Paper presented at the International Conference on Port and Maritime R\&D and Technology, Singapore.

ECE, U. (1998). UN/LOCODE-Code for Ports and Other Locations (Vol. 16): Recommendation.

Gharakhani, M., Rasouli, S., \& Babakhani, M. (2011). A robust LINMAP for EFQM self assessment. Management Science Letters, 1(2), 213-222.

Hayuth, Y., \& Fleming, D. K. (1994). Concepts of strategic commercial location: the case of container ports. Maritime Policy and Management, 21(3), 187-193.

Hwang C.L., \& K., Y. (1981). Multiple Attributes Decision Making Methods and Applications. Berlin: Springer.

IMO. (2014). International Maritime Organization (IMO). from IMO.org

James, B., \& Gail, B. (1988). The perception of route competition via seaports in the European communities. Maritime Policy and Management, 15(1), 35-55.

Kuo, T., \& Chu, C. (2000). A decision-making model for the selection of calling container port. Paper presented at the The 5th symposium on transportation network, Taiwan. 
L., H. C., \& K., Y. (1981). Multiple Attributes Decision Making Methods and Applications. Berlin: Springer.

Malchow, M. B., \& Kanafani, A. (2004). A disaggregate analysis of port selection. Transportation Research Part E: Logistics and Transportation Review, 40(4), 317-337.

Opricovic, S., \& Tzeng, G.-H. (2004). Compromise solution by MCDM methods: A comparative analysis of VIKOR and TOPSIS. European Journal of Operational Research, 156(2), 445-455.

Pahlavani, A. (2009). Investment prioritization through group decision making method of hierarchical TOPSIS in fuzzy environment. Journal of Industrial Management, 1(2), 35-54.

Qi, X., \& Song, D.-P. (2012). Minimizing fuel emissions by optimizing vessel schedules in liner shipping with uncertain port times. Transportation Research Part E: Logistics and Transportation Review, 48(4), 863-880.

Reza, Z., \& Masoud, H. (2009). Facility location: concepts, models, algorithms and case studies: Springer-Verlag Berlin Heidelberg.

Rietveld, P., \& Ouwersloot, H. (1992). Ordinal data in multicriteria decision making, a stochastic dominance approach to siting nuclear power plants. European Journal of Operational Research, $56(2), 249-262$.

Saaty, T. L. (1980). The analytic hierarchy process: planning, priority setting, resources allocation. New York: McGraw.

Saaty, T. L. (1988). What is the analytic hierarchy process? : Springer.

Slack, B. (1985). Containerization, inter-port competition, and port selection. Maritime Policy and Management, 12(4), 293-303.

Soltanmohammad, N., Modiri, M., \& Hafashjani, K. (2013). Ranking important factors influencing organizational strategy in selecting distribution channels with the approach of FMCDM. Uncertain Supply Chain Management, 1(4), 253-263.

Spohrer, G., \& Kmak, T. (1984). Qualitative-analysus used in evaluating plant location scenarios. Industrial Engineering, 16(8), 52-\&.

Sternberg, R. (2000). The successful factors of one ocean transshipment center, the case study of one Italian port. The Journal of Chinese Ports, 29(2), 13-18.

Stevenson, W. Production/Operation Management. 1993. Richard D. Irwin Inc., Illinois.

Thomson, B. (1998). Structure changes in the maritime industry's impact on the inter-port competition in container trade. Paper presented at the International conference on shipping development and port management.

Tompkin, J., White, J., Bozer, Y., Frazelle, E., Tanchoco, J., \& Trevino, J. (1984). Facilities Planning. Wiley, New York.

UNCTAD. (2015). Review of Maritime Transportation. Paper presented at the Paper Presented at the United Nations Conference on Trade and Development, New York and Geneva. 